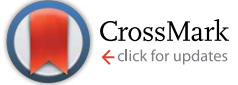

Cite this: J. Mater. Chem. A, 2015, 3, 20983

Received 21st July 2015

Accepted 8th September 2015

DOI: $10.1039 / c 5 t a 05567 a$

www.rsc.org/MaterialsA

\section{Poly(ether ether ketone) (PEEK)-based graft-type polymer electrolyte membranes having high crystallinity for high conducting and mechanical properties under various humidified conditions $\dagger$}

\author{
Takashi Hamada, Shin Hasegawa, Hideyuki Fukasawa, Shin-ichi Sawada, \\ Hiroshi Koshikawa, Atsumi Miyashita and Yasunari Maekawa*
}

\begin{abstract}
Poly(ether ether ketone)-based graft-type polymer electrolyte membranes (PEEK-PEMs) with wide ion exchange capacity (IEC) ranges were prepared by radiation-induced graft polymerization for investigating the relative humidity $(\mathrm{RH})$ dependence of their electrochemical and mechanical properties at $80{ }^{\circ} \mathrm{C}$ for fuel cell applications. The proton conductivity ranges of $1.73-3.08 \mathrm{mmol} \mathrm{g} \mathrm{I}^{-1} \mathrm{IECs}$ at $30 \%$ and 95\% RH were 0.001-0.009 and 0.108-0.431 S cm c $^{-1}$, respectively. Unlike aromatic hydrocarbontype PEMs, PEEK-PEMs' conductivity exhibited less dependence on RH. PEEK-PEMs with IECs > 3.08 mmol g ${ }^{-1}$ exhibited a similar conductivity $\left(0.009 \mathrm{~S} \mathrm{~cm}^{-1}\right)$ under $30 \% \mathrm{RH}$ and showed 1.4 times higher tensile strength (14 MPa) under $100 \% \mathrm{RH}$ at $80{ }^{\circ} \mathrm{C}$ in comparison to Nafion 212 . The MEA fabricated by the PEEK-PEM with IEC $=2.45 \mathrm{mmol} \mathrm{g}^{-1}$ showed the maximum power densities $\left(E_{\max }\right)$ of 860 and 826 $\mathrm{mW} \mathrm{cm} \mathrm{c}^{-2}$ at 2140 and $2180 \mathrm{~mA} \mathrm{~cm}^{-2}$ under $100 \%$ and $30 \% \mathrm{RH}$, respectively. In particular, PEEK-PEM showed low $\mathrm{RH}$ dependence for $E_{\max }$, which was 2.5 times higher than that of Nafion 212 at $30 \% \mathrm{RH}$. The X-ray scattering analyses revealed that the crystallinity of approximately $28-32 \%$ was maintained and propagated during the graft polymerization of graft-type PEEK-PEMs. The abovementioned unique structures were the origins of higher conductivity and tensile strengths compared with conventional PEMs.
\end{abstract}

\section{Introduction}

Polymer electrolyte membrane fuel cells (PEMFCs) can produce energy from hydrogen and oxygen without air pollution and have therefore attracted attention for use in next-generation energy applications such as fuel cell vehicles and stationary cogeneration systems to replace fossil fuel resources. ${ }^{1}$ The polymer electrolyte membrane (PEM) is a particularly important part of PEMFCs because it separates the two electrodes and transports protons from the anode to the cathode., ${ }^{2,3}$ Currently, sulfonated perfluoropolymers such as Nafion ${ }^{\mathrm{TM}}$ have been used mostly as PEMs. However, these materials cause several issues such as high fuel crossover and a limited operating temperature range of up to $80{ }^{\circ} \mathrm{C}$ (low glass transition temperature). ${ }^{4-6}$ Numerous sulfonated aromatic hydrocarbon-type polymers such as poly(ether ether ketone), ${ }^{7,8}$ poly(phenylene sulfone), ${ }^{9-12}$ poly(arylene ether ketone), ${ }^{13}$ polyimides, ${ }^{14-16}$ poly(phenylene), ${ }^{17,18}$ and polybenzimidazole ${ }^{19,20}$ have been designed and synthesized as alternatives to perfluorinated PEMs because of their rigid aromatic

Functional Polymer Group, Quantum Beam Science Directorate, Japan Atomic Energy Agency (JAEA), 1233 Watanuki, Takasaki, Gunma 370-1292, Japan. E-mail: maekawa. yasunari@jaea.go.jp; Fax: +8127346 9687; Tel: +81273469410

$\dagger$ Electronic supplementary information (ESI) available. See DOI: 10.1039/c5ta05567a backbone, which gives them higher thermal stability and mechanical strength.

Recently, for PEMs, high proton conductivity and mechanical properties under low and high relative humidity $(\mathrm{RH})$ conditions have become a main concern, respectively, because these properties control power generation efficiency and durability under the extreme operating conditions of fuel cell systems. One solution to this problem is to increase ion exchange capacity (IEC), which is related to PEM conductivity. ${ }^{19,21,22}$ However, PEMs with higher IEC exhibit severe damage in a hydrated state under flooding conditions. Unfortunately, PEMs based on hydrocarbon polymers show much lower proton conductivity at low RH compared with the perfluorinated PEMs, although their proton conductivities are almost the same in high-RH ranges. One promising strategy for improving conductivity even with fewer water molecules in PEMs is the use of multiblock-type aromatic hydrocarbon polymers that comprise hydrophilic and hydrophobic units, e.g., block-type poly(arylene ether sulfone)s and poly(phenylene) block copolymers. ${ }^{23-27}$ However, multiblock-type aromatic hydrocarbon polymers have critical issues that include insufficient durability and the fact that their conductivity significantly depends on $\mathrm{RH}$. Another approach to overcome this problem is using aromatic hydrocarbon-based PEMs that have locally condensed sulfonic 
acid groups or perfluoroalkyl sulfonic acid groups, the so-called, superacid. ${ }^{28-30}$ Although these PEM materials show a pronounced hydrophilic/hydrophobic phase-separated morphology with well-interconnected proton transport pathways leading to high conductivity at low $\mathrm{RH}$, the mechanical properties of PEMs were evaluated only at room temperature under relatively dry conditions but not under hydrated conditions at higher temperatures.

Graft-type PEMs, which are prepared by radiation-induced graft polymerization of monomers and the subsequent sulfonation reaction of the graft polymers, can overcome the abovementioned problems because the graft-type PEM comprises substrate films that have a mechanically tough crystalline phase and various functional grafted polymer phases directly bonded to the polymer main chain..$^{31-44}$ Furthermore, the introduction of sulfonated graft side chains into the polymer main chain is an excellent approach to PEM preparation because the IEC values can be controlled by easily changing the degree of grafting. Recently, we studied the RH dependence of the electrochemical and mechanical properties of poly(styrene sulfonic acid) (PSSA)-grafted poly(ethylene-co-tetrafluoroethylene) polymer electrolyte membranes (ETFE-PEMs) over a wide IEC range. ${ }^{45,46}$ Unlike aromatic hydrocarbon-type PEMs, the proton conductivity of ETFE-PEMs has less RH dependence because hydrophilic grafted polymers provide clearer phase separation from the hydrophobic ETFE substrate, thereby maintaining conducting channels even under dry conditions. Therefore, ETFE-PEMs with IEC $>2.7 \mathrm{mmol} \mathrm{g}^{-1}$ exhibited higher conductivity $\left(>0.009 \mathrm{~S} \mathrm{~cm}^{-1}\right)$ at $30 \% \mathrm{RH}$ and showed comparable tensile strength of approximately $10 \mathrm{MPa}$ at $100 \%$ $\mathrm{RH}$ and $80^{\circ} \mathrm{C} .{ }^{45}$

To overcome the abovementioned trade-off relationship between conductivity and mechanical properties, we selected poly(ether ether ketone) (PEEK), which is one of the typical super engineering plastics that possess the highest mechanical and thermal properties, as the base substrate film. We succeeded in achieving radiation-induced graft polymerization of styrene and ETSS on low crystalline PEEK substrates via a three-step process, as shown in Scheme 1. The three steps are thermal graft polymerization of divinylbenzene (DVB) into the PEEK substrates and subsequent radiation-induced graft polymerization of ETSS, followed by hydrolysis of the ester group in the graft polymers. As a result, the prepared PSSA-grafted PEEK (PEEK-PEM) with an IEC of $1.36 \mathrm{mmol} \mathrm{g}^{-1}$ showed 1.3 times higher conductivity under the equilibrated hydration conditions and 3 times higher tensile

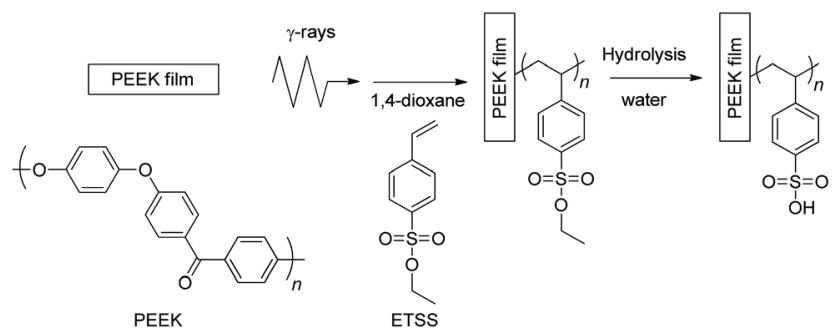

Scheme 1 Radiation induced-graft polymerization of ETSS onto PEEK substrates and subsequent hydrolysis of ethyl ester groups. strength under dry conditions at room temperature, compared with the corresponding values of Nafion $212 .{ }^{47}$ The well-balanced electrochemical and mechanical properties of PEEK-PEMs encouraged us to develop PEEK-PEMs with higher IEC ranges to improve proton conductivities under low $\mathrm{RH}$ conditions while retaining the mechanical properties to some extent under high RH conditions. In this study, we report the RH dependence of the electrochemical and mechanical properties of PEEK-PEMs in a wide IEC range in comparison with those of perfluorinated PEMs, as well as on fuel cell performance. Moreover, we carefully monitored changes in the crystallinity of the PEEK substrates during the preparation procedures such as DVB introduction, radiation-induced grafting, and hydrolysis using X-ray diffraction (XRD) to elucidate the origin of higher conductivity and mechanical strength.

\section{Experimental}

\section{Materials}

PEEK films with a thickness of $16 \mu \mathrm{m}$ and $11 \%$ crystallinity were purchased from Victrex plc, Japan and cut into a size of $10 \times$ $9 \mathrm{~cm}$. Ethyl 4-styrenesulfonate (ETSS) was provided by Tosoh Co., Japan and used as received. DVB (technical grade, 80\%) was purchased from Sigma-Aldrich Co., Japan and used without purification. 1,4-Dioxane was purchased from Wako Pure Chemical Industries, Ltd and dried over molecular sieves before use. Other solvents were purchased from Wako Pure Chemical Industries, Ltd and used as received. Sodium chloride ( $\mathrm{NaCl}$, sodium hydroxide $(\mathrm{NaOH})$, and hydrochloric acid of analytical grade were purchased from Wako Pure Chemical Industries, Ltd. Pure water was obtained from a Millipore Milli-Q UV system. Nafion 212 obtained from DuPont was pretreated by boiling for $1 \mathrm{~h}$ in a $3 \% \mathrm{H}_{2} \mathrm{O}_{2}$ solution, washing in hot pure water for $1 \mathrm{~h}$, boiling for $1 \mathrm{~h}$ in $1 \mathrm{M} \mathrm{H}_{2} \mathrm{SO}_{4}$, and final rinsing in hot water again for $1 \mathrm{~h}$. Nafion perfluorinated ion-exchange resin, $20 \mathrm{wt} \%$ soln of lower aliphatic alcohols $/ \mathrm{H}_{2} \mathrm{O}$ mixture was purchased from Sigma-Aldrich Co., Japan and used without purification. The $\mathrm{Pt} / \mathrm{C}$ catalyst was purchased from Tanaka Kikinzoku kogyo Ltd, Japan.

\section{Preparation of PEEK-PEMs}

PEEK films were added to a dried Schlenk tube. After the air was removed and purged with argon, a solution of DVB/1,4-dioxane (25 vol\%) was added to the Schlenk tube in an argon atmosphere and heated in a water bath at $50{ }^{\circ} \mathrm{C}$ for $24 \mathrm{~h}$. The obtained films were washed with 1,4-dioxane and immersed in $100 \mathrm{~mL}$ of 1,4 -dioxane at $50{ }^{\circ} \mathrm{C}$ for $12 \mathrm{~h}$ to remove residual monomers. The obtained films (PEEK-DVB) were dried in a vacuum at $40^{\circ} \mathrm{C}$ for $24 \mathrm{~h}$.

A PEEK-DVB film in a Schlenk tube was irradiated with ${ }^{60} \mathrm{Co}$ $\gamma$-rays at a dose rate of $10 \mathrm{kGy} \mathrm{h}^{-1}$ for $16 \mathrm{~h}$ under an argon atmosphere at room temperature. Then, a solution of $15 \mathrm{~mL}$ of ethyl 4-styrenesulfonate and $15 \mathrm{~mL}$ of 1,4-dioxane was degassed by argon bubbling and added to the Schlenk tube containing the PEEK-DVB film. The mixture was heated at $80{ }^{\circ} \mathrm{C}$ under an argon atmosphere for 6-24 h. Grafted PEEK films were taken 
out, and washed with acetone. To remove residual ethyl 4-styrenesulfonate and the free polymer on the film surfaces, grafted PEEK films were soaked in a large amount of acetone overnight. The obtained films were dried in a vacuum at $40{ }^{\circ} \mathrm{C}$ for $24 \mathrm{~h}$.

The hydrolysis of ethyl ester was carried out in distilled water at $95{ }^{\circ} \mathrm{C}$ for $24 \mathrm{~h}$ to obtain PEEK-PEM.

\section{Electrolyte properties of PEEK-PEMs}

Grafting degrees (GDs) were estimated from the mass weighting as follows:

$$
\mathrm{GD}(\%)=\frac{W_{\mathrm{g}}-W_{0}}{W_{0}} \times 100
$$

In this equation, $W_{0}$ and $W_{\mathrm{g}}$ are denoted as the weight of films before and after graft polymerization, respectively.

The degree of hydrolysis and ion exchange capacity was determined by a titration method. The dried films were immersed in $25 \mathrm{~mL}$ of an aqueous $3 \mathrm{M} \mathrm{NaCl}$ solution overnight (or $24 \mathrm{~h}$ ) to reach equilibrium. Then, the remaining solution was titrated with $0.01 \mathrm{M} \mathrm{NaOH}$ solution by using an automatic titrator. The IEC was calculated according to the following equation (eqn (2)):

$$
\mathrm{IEC}=\frac{0.01 \times V_{\mathrm{NaOH}}}{W_{\mathrm{d}}}
$$

where $V_{\mathrm{NaOH}}$ is the volume of $0.01 \mathrm{M} \mathrm{NaOH}$ solution and $W_{\mathrm{d}}$ is the weight of dried films. The weight of the membranes was quickly measured after the membranes were taken out.

The degree of hydrolysis, namely, the hydrolysis degree (HD) is calculated by the following equation (eqn (3)):

$$
\mathrm{HD}(\%)=\frac{0.01 \times V_{\mathrm{NaOH}}}{W_{\mathrm{g}} \times \frac{\mathrm{GD} /(\mathrm{GD}+100)}{M}} \times 100
$$

Water uptake (WU) was defined by the following equation (eqn (4)):

$$
\mathrm{WU}=\frac{\left(W_{\text {wet }}-W_{\text {dry }}\right)}{W_{\text {dry }}} \times 100
$$

The membranes were fully hydrated in water at room temperature, and lightly wiped with Kimwipes to remove excess water on the surface. To measure the RH dependence of the WU and hydration number, the membranes were placed in a humidity controlled chamber under different RH conditions at $80{ }^{\circ} \mathrm{C}$ for $2 \mathrm{~h}$. After the membrane was taken out, the membrane was put into a plastic bag and sealed to prevent vapor absorption or desorption and quickly weighed on a microbalance. The water uptake and hydration number were calculated using the following equations (eqn (5) and (6)), respectively.

$$
\lambda=\frac{\left[\mathrm{H}_{2} \mathrm{O}\right]}{\left[\mathrm{SO}^{3-}\right]}=\frac{\left(W_{\mathrm{w}}-W_{\mathrm{d}}\right) / 18}{\mathrm{IEC} \times W_{\mathrm{d}} / 1000} \times 100
$$

The membrane was placed between two platinum electrodes, and the proton conductivity in the plane direction of the membrane was measured by impedance spectroscopy at room temperature. The membrane was placed in an ESPEC PR-2K temperature/humidity-controlled chamber under the $\mathrm{RH}$ ranging from 30 to $95 \%$ at $80{ }^{\circ} \mathrm{C}$. The proton conductivity was calculated from the obtained resistance $(R)$ according to the following equation (eqn (6)):

$$
\sigma=\frac{d}{R S}
$$

where $d(\mathrm{~cm})$ is the thickness of the membrane and $S\left(\mathrm{~cm}^{2}\right)$ is the contact area of two electrodes.

\section{Characterization of PEEK-DVB, grafted PEEK, and PEEK-PEM}

Thermogravimetric analysis (TGA) was performed on a TGA Thermal Plus/TG-DTA8120 (Rigaku, Japan) at a heating rate of $10{ }^{\circ} \mathrm{C} \mathrm{min}{ }^{-1}$ and a nitrogen flow rate of $50 \mathrm{~mL} \mathrm{~min}^{-1}$. Differential scanning calorimetry (DSC) was performed using a Thermo Plus2/DSC8230 with the specimen of $4-5 \mathrm{mg}$ at a heating rate of $10{ }^{\circ} \mathrm{C} \mathrm{min}^{-1}$ to the temperature of $900{ }^{\circ} \mathrm{C}$. Tensile tests were performed using an STA-1150 (A\&D Co., Ltd, Japan) and an Instron-4302 universal testing instrument. The mechanical properties of PEEK-PEMs were measured at $100 \%$ $\mathrm{RH}$ and $80{ }^{\circ} \mathrm{C}$ at a constant crosshead speed of $10 \mathrm{~mm} \mathrm{~min}{ }^{-1}$. The tensile strength of PEEK-PEMs was calculated as an average of five samples. The XRD experiment was undertaken with a Rigaku SmartLab using CuK radiation $(\lambda=1.54 \AA)$ at $40 \mathrm{kV}$ and $45 \mathrm{~mA}$ in the $2 \theta$ range from 5 to $40^{\circ}$. The degree of crystallinity (DOC) of PEEK-PEMs was calculated using the following equation (eqn (7)):

$$
\operatorname{DOC}(\%)=\frac{\int_{0}^{\infty} I_{\mathrm{cr}}(q) q^{2} \mathrm{~d} q}{\int_{0}^{\infty} I_{\text {total }}(q) q^{2} \mathrm{~d} q}=\frac{I_{\mathrm{cr}}}{I_{\mathrm{cr}}+I_{\mathrm{am}}} \times 100
$$

where $I_{\mathrm{cr}}$ and $I_{\mathrm{am}}$ are the integrated values of the PEEK crystalline peak and the amorphous peaks, respectively.

The degree of crystallinity of the PEEK phase in PEEK-PEMs (DOC') was estimated by taking into account the introduction of poly(styrene sulfonic acid) and using the following equation (eqn (8)):

$$
\operatorname{DOC}^{\prime}(\%)=\frac{\int_{0}^{\infty} I_{\mathrm{cr}}(q) q^{2} \mathrm{~d} q}{\int_{0}^{\infty} I_{\text {total }}(q) q^{2} \mathrm{~d} q}=\frac{I_{\mathrm{cr}}}{I_{\mathrm{cr}}+I_{\mathrm{am}}\left(\frac{100}{100+\mathrm{GD}}\right)} \times 100
$$

\section{The membrane electrode assembly (MEA) fabrication and fuel cell test}

$200 \mathrm{mg}$ of $\mathrm{Pt} / \mathrm{C}$ and $0.2 \mathrm{~mL}$ of $20 \mathrm{wt} \%$ Nafion perfluorinated ionexchange resin were dispersed in a mixture of $4.8 \mathrm{~mL}$ of water and $4.8 \mathrm{~mL}$ of methanol. The solution mixture was sonicated for $3 \mathrm{~h}$ and coated onto the gas diffusion media $(3 \mathrm{~cm} \times 3 \mathrm{~cm})$ of carbon and Teflon by spraying to prepare the electrode. The 
obtained electrode was dried at $95{ }^{\circ} \mathrm{C}$ for $10 \mathrm{~min}$. The Pt loading was estimated to be $0.4 \mathrm{mg} \mathrm{cm} \mathrm{cm}^{-2}$ from the weight of the gas diffusion media before and after spraying the solution mixture. The PEEK-PEM $(5.0 \mathrm{~cm} \times 5.0 \mathrm{~cm})$ was sandwiched by the electrode, and hot-pressed at $170{ }^{\circ} \mathrm{C}$ under $1 \mathrm{MPa}$ for $1 \mathrm{~min}$ and cooled to room temperature to obtain an MEA with an active area of $5 \mathrm{~cm}^{2}$ and Pt loading of $0.4 \mathrm{mg} \mathrm{cm} \mathrm{cm}^{-2}$. The MEA of the hybrid PEM was assembled into a cell holder. The fuel cell testing was performed at a cell temperature of $80{ }^{\circ} \mathrm{C}$ under different RH of $100 \%$ and $30 \%$ RH using a single fuel cell device (Micro equipment Inc. me-300FC). During the cell test, hydrogen and oxygen were supplied at a flow rate of $50 \mathrm{~mL}$ $\min ^{-1}$ each to the anode and cathode, respectively. The $I-V$ curves were measured in the range of $0.9-0.3$ with a step repeatedly, typically a few times, until the fuel cell performance reached the steady state.

\section{Results and discussion}

\section{Preparation and characterization of PEEK-PEMs}

PEEK-PEMs were prepared via a three-step process, as previously reported (Scheme 1). DVB was introduced into the PEEK substrates by thermal polymerization at $50{ }^{\circ} \mathrm{C}$ for $24 \mathrm{~h}$ in 1,4dioxane. By TGA measurements, the amount of DVB incorporated into the PEEK substrates was estimated to be $2-3 \mathrm{wt} \% .^{34,35}$ Next, we used the DVB-containing PEEK films as base polymer films for further radiation-induced graft-polymerization. The PEEK film was irradiated with a dose of $160 \mathrm{kGy}$ at room temperature. The graft polymerization of ETSS proceeded smoothly in a 50 vol\% 1,4 -dioxane solution at $80{ }^{\circ} \mathrm{C}$. We controlled the GD range from $70 \%$ to $207 \%$ by employing grafting periods of 6-24 h, as listed in Table 1 . This is because PEMs which possess both sufficient conductivity and mechanical properties under a wide $\mathrm{RH}$ range should have IECs ranging from 1.5 to 3.5 judging from the $\mathrm{RH}$ dependence of fluoropolymer-based ETFE-PEMs, which we previously reported..$^{45}$ The grafted-PEEK films with GDs of $70-207 \%$ were hydrolyzed in water at $95{ }^{\circ} \mathrm{C}$ for $24 \mathrm{~h}$ to convert ethyl sulfonate into sulfonic acid in a yield range of $86-98 \%$. Consequently, the prepared PEEK-PEMs showed IECs ranging from 1.73 to $3.08 \mathrm{mmol} \mathrm{g}^{-1}$. Since most of the graft-type PEMs prepared by radiationinduced graft-polymerization including PEEK-PEMs are insoluble in neither organic nor aqueous solutions, the chemical structure of the PEEK-PEMs had been characterized using ATRIR and TGA-DSC analysis. The thermal stability of the PEEK-
PEMs had also been investigated using TGA-DSC in the previous papers. $^{34,36,47,48}$

PEEK-PEMs with an IEC of $2.22 \mathrm{mmol} \mathrm{g}^{-1}$ exhibited a proton conductivity of $0.103 \mathrm{~S} \mathrm{~cm}^{-1}$, which is higher than that of Nafion 212. In particular, for PEEK-PEMs with an IEC of 3.08 $\mathrm{mmol} \mathrm{\textrm {g } ^ { - 1 }}$, the proton conductivity reached $0.210 \mathrm{~S} \mathrm{~cm}^{-1}$, which is 3 times higher than that of Nafion 212. As expected, the large quantity of poly(styrene sulfonic acid) as the graft polymer led to a significant enhancement in conductivity. Furthermore, the water uptake, which ranged from $25 \%$ to $120 \%$, increased with increasing IEC. In a previous report, we reported that ETFEPEMs with IECs ranging from 0.52 to $3.3 \mathrm{mmol} \mathrm{g}^{-1}$ showed proton conductivities of $0.002-0.233 \mathrm{~S} \mathrm{~cm}^{-1}$ and water uptake of $2.7-168 \%{ }^{45}$ The proton conductivities of PEEK-PEMs were similar to those of ETFE-PEMs because of their similar IEC values. However, the water uptake of PEEK-PEMs was lower than that of ETFE-PEMs. PEEK-PEMs with an IEC of $2.22 \mathrm{mmol} \mathrm{g}^{-1}$ exhibited a WU of $38 \%$, which was similar to that of Nafion 212 with an IEC of $0.8 \mathrm{mmol} \mathrm{g}^{-1}(39 \%)$. This unique property is important for PEMs because a high water uptake causes severe swelling of PEMs, which damages membranes during fuel cell operation. In particular, despite the presence of large amounts of hydrophilic sulfo groups (higher IECs), the PEEK-based PEMs suppressed swelling of the hydrophilic graft chain with water.

\section{Proton conductivity of PEEK-PEMs under various RH}

As mentioned in the Introduction, the $\mathrm{RH}$ dependence of proton conductivity and mechanical strength are currently the main concerns because these properties are directly related to the power generation efficiency and durability of fuel cells. Thus, we examined at $80{ }^{\circ} \mathrm{C}$ the $\mathrm{RH}(30-95 \% \mathrm{RH})$ dependence of the proton conductivity of the PEEK-PEMs with IECs of 1.73$3.08 \mathrm{mmol} \mathrm{g}^{-1}$ (GD $\left.=70-207 \%\right)$ together with that of Nafion 212 as a reference, as shown in Fig. 1.

The PEEK-PEMs with various IECs covered a wide range of conductance with more than three orders of magnitude, ranging from 0.001 to $0.009 \mathrm{~S} \mathrm{~cm}^{-1}$ and from 0.108 to $0.431 \mathrm{~S}$ $\mathrm{cm}^{-1}$ at $30 \%$ and $95 \% \mathrm{RH}$, respectively. At RHs higher than $80 \%$, the proton conductivity of PEEK-PEMs with IECs higher than $2.22 \mathrm{mmol} \mathrm{g}^{-1}$ was found to be comparable with or higher than that of Nafion 212 . At $30 \% \mathrm{RH}$, the proton conductivity of the PEEK-PEM with an IEC of $3.08 \mathrm{mmol} \mathrm{g}^{-1}$ increased with increasing IEC and reached a value similar to that of Nafion 212.

Table 1 Radiation induced-graft polymerization and hydrolysis results and properties of PEEK-PEMs

\begin{tabular}{|c|c|c|c|c|c|}
\hline GD of ETSS (\%) & HD (\%) & IEC $\left(\mathrm{mmol} \mathrm{g}^{-1}\right)$ (Cal.) & IEC $\left(\mathrm{mmol} \mathrm{g}^{-1}\right)($ Exp.) & WU (\%) & $\sigma\left(\mathrm{S} \mathrm{cm}^{-1}\right)$ \\
\hline 70 & 89 & 1.78 & 1.73 & 25 & 0.068 \\
\hline 85 & 98 & 2.09 & 2.22 & 38 & 0.103 \\
\hline 134 & 84 & 2.75 & 2.36 & 44 & 0.119 \\
\hline 142 & 89 & 2.84 & 2.64 & 80 & 0.154 \\
\hline 171 & 86 & 3.10 & 2.74 & 88 & 0.170 \\
\hline
\end{tabular}




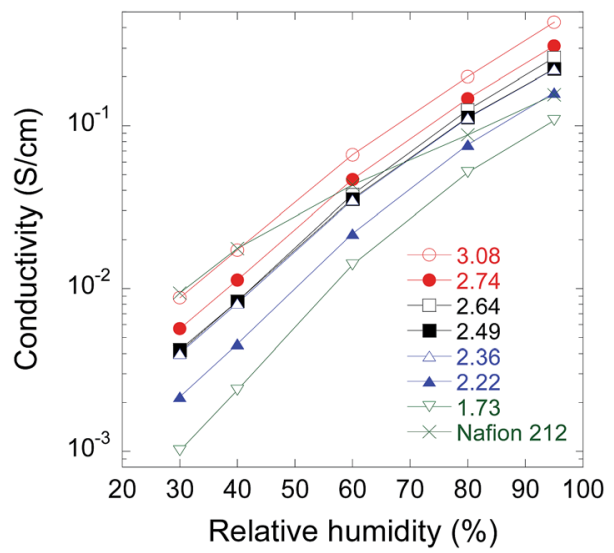

Fig. 1 Relative humidity dependence of proton conductivity at $80^{\circ} \mathrm{C}$ for PEEK-PEMs with IECs of $1.73-3.08 \mathrm{mmol} \mathrm{g}^{-1}$ and Nafion 212.

The slopes in the plots of $\log \sigma$ as a function of $\mathrm{RH}$ were employed as feasible parameters for evaluating the RH dependence of conductance for PEMs, which were designed for achieving high conductivity under lower RH conditions. The slope of PEEK-PEMs became slightly steeper when IEC increased from 1.73 to $3.08 \mathrm{mmol} \mathrm{g}^{-1}$. The PEEK-PEM with the highest IEC (3.08 mmol $\mathrm{g}^{-1}$ ) showed a slope steeper than that of Nafion 212. However, the proton conductivity of PEEK-PEMs was less dependent on RH compared with the aromatic hydrocarbon-type PEMs such as aliphatic/aromatic polyimide and ethynyl-terminated sulfonated-fluorinated poly(arylene ether)s, the conductance of which changed by $4-5$ orders of magnitude when the $\mathrm{RH}$ changed from $100 \%$ to $30 \%$. The $\mathrm{RH}$ dependence of proton conductivity of the PEEK-PEMs with high IECs is similar to that of fluorinated polymer-based graft-type PEMs (ETFE-PEMs), which we previously reported. Two different types of graft-type PEMs showed much better RH dependence than conventional aromatic hydrocarbon PEMs. Hence, adequate phase separation of the ion channels composed of graft polymer chains should be ensured from the hydrophobic polymer substrates (ETFE and PEEK) in comparison with the less phase-separated hydrocarbon-type PEMs such as PEEK, as we have proved by SAXS and SANS measurements. ${ }^{47}$

The humidity dependence of water uptake and hydration number $\lambda$, which is defined as the number of water molecules per sulfo group in PEMs, was plotted as a function of $\mathrm{RH}$ for PEEKPEMs with IECs ranging from $1.73-3.08 \mathrm{mmol} \mathrm{g}^{-1}$ at $80{ }^{\circ} \mathrm{C}$, together with Nafion 212 as a reference, as shown in Fig. 2. At higher RH (95\%), the PEEK-PEMs with IECs of 1.73, 2.36, and 3.08 mmol g ${ }^{-1}$ showed higher water uptakes (50\%, 62\%, and 102\%) than Nafion 212. In high RH regions, the high water uptakes of PEEK-PEMs were attributed to high IECs compared with Nafion 212, which has an IEC of $0.8 \mathrm{mmol} \mathrm{g}^{-1}$. As previously reported for many hydrocarbon-type and graft-type PEMs, ${ }^{7-20}$ the water uptake of PEEK-PEMs decreased with decreasing $\mathrm{RH}$ and at $30 \% \mathrm{RH}$. The PEEK-PEMs with IECs of $1.73,2.36$, and $3.08 \mathrm{mmol} \mathrm{g}^{-1}$ showed water uptakes of $9.7 \%, 16 \%$, and $17 \%$, which corresponded to $\lambda$ values of 3.1, 3.7, and 3.1, respectively. The $\lambda$ values were relatively close to that of Nafion $212(\lambda=2.95)$. As many groups have already reported, PEM conductivity under low RH conditions was explained in terms of water uptake and the hydration number, $\lambda$. Contrary to conventional aromatic hydrocarbon-type PEMs with high IEC levels, which showed lower $\lambda$ than Nafion under low RH conditions, the $\lambda$ of the PEEK-PEMs was similar to that of Nafion. Accordingly, the $\lambda$ of PEEK-PEMs with an IEC of $3.08 \mathrm{mmol} \mathrm{g}^{-1}$ was equal to that of Nafion even under $30 \%$ RH. Notably, not only high IEC levels but also high retention of water molecules affords high proton conductivity even under $30 \% \mathrm{RH}$ and suppresses the humidity dependence of graft-type PEMs compared with other aromatic hydrocarbon-type PEMs. Recently, we clarified that ETFE-PEMs with IECs greater than $2.7 \mathrm{mmol} \mathrm{g}^{-1}$ possess ion channels composed of poly(styrene sulfonic acid) grafts located outside the crystallite network domains by small-angle X-ray scattering experiments. These ion channels are well interconnected around the crystallites, which endow ETFE-PEMs with high conductivity under low RH conditions. Similarly, PEEKPEMs with high IECs should have similar well-interconnected ion channels, composed of poly(styrene sulfonic acid) of PEEK-PEMs.

\section{Mechanical properties of PEEK-PEMs under humidified conditions}

The mechanical properties of PEMs under humid conditions such as flooding govern their durability under severe operating conditions of fuel cell systems because PEMs absorb large
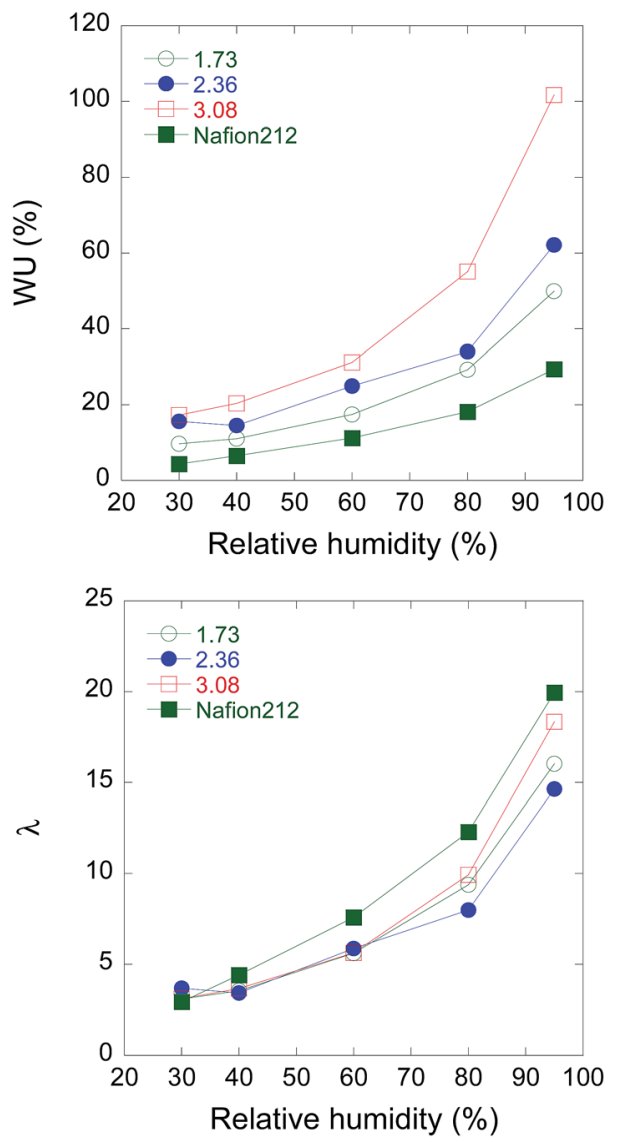

Fig. 2 Relative humidity dependence of water uptake (a) and hydration number (b) for PEEK-PEMs with IECs of 1.73, 2.36, and $3.08 \mathrm{mmol} \mathrm{g}^{-1}$ and Nafion 212 as a reference at $80{ }^{\circ} \mathrm{C}$. 
amounts of water, which induces large stresses in the membranes resulting in their degradation. Thus, we examined the TS and elongation at break of the PEEK-PEMs with IECs of 1.73-3.08 mmol $\mathrm{g}^{-1}$ at $80{ }^{\circ} \mathrm{C}$ under $100 \% \mathrm{RH}$. This was compared with Nafion 212 as a reference, as shown in Fig. 3. The PEEK-PEM with an IEC of $1.73 \mathrm{mmol} \mathrm{g}^{-1}$ showed higher TS (35 MPa) than Nafion 212 (10 MPa). In the IEC range of 1.73$3.08 \mathrm{mmol} \mathrm{g}^{-1}$, the TS of PEEK-PEMs gradually decreased with an increase in IEC, but it still remained 1.4 times higher than that of Nafion $212(14 \mathrm{MPa})$. It was reported that the lower TS of graft-type PEMs with higher IECs was mainly because of higher water uptake but not because of the introduction of PSSA graft polymers. However, the TS of PEEK-PEMs across the entire IEC range was much higher than that of Nafion 212, and the PEEKPEM with an IEC of $2.22 \mathrm{mmol} \mathrm{g}^{-1}$ showed the same level of conductivity but 2.6 times higher TS (26 MPa) compared with Nafion 212.

Several groups have measured the TS of aromatic hydrocarbon-type PEMs under humidified conditions, such as sulfonated poly(aryl ether nitrile) (18-41 MPa, hydrated state, r.t.), ${ }^{49}$ poly(aryl ether ketone) containing tetra-sulfonated side chains (25-46 Mpa, 50\% RH, r.t.), ${ }^{50}$ sulfonated poly(sulfide sulfone imide) copolymers (13-29 $\mathrm{MPa}$, hydrated state, r.t.), ${ }^{51}$ poly(arylene ether ether nitrile) (18-22 MPa, 50\% RH, $\left.20{ }^{\circ} \mathrm{C}\right){ }^{52}$
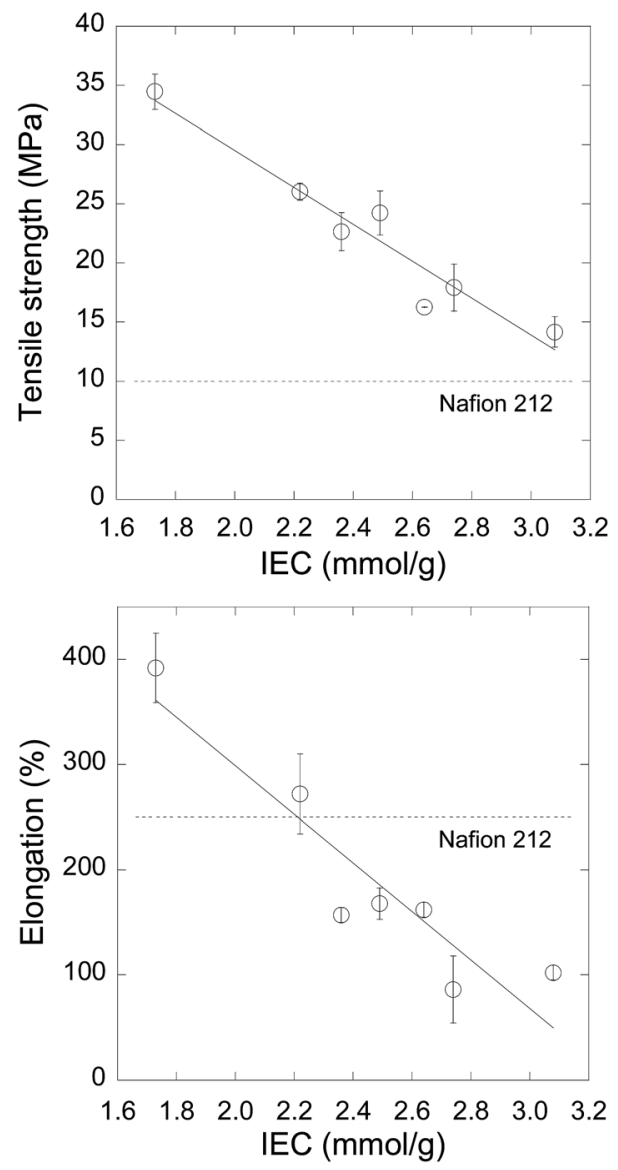

Fig. 3 Tensile strength (a) and elongation at break (b) of PEEK-PEMs with IECs of $1.73-3.08 \mathrm{mmol} \mathrm{g}^{-1}$ and that of Nafion 212 (dotted lines as a reference) under $100 \% \mathrm{RH}$ at $80{ }^{\circ} \mathrm{C}$. and poly(phenylene ether) (34-54 MPa, 50\% RH, $\left.20{ }^{\circ} \mathrm{C}\right) .{ }^{53}$ These values were measured under mild conditions such as low temperature or low $\mathrm{RH}$ even though the mechanical properties of membranes were influenced by water uptake; thus, TS decreased with increasing $\mathrm{RH}$ in most of the aromatic hydrocarbon-type PEMs. In our previous study, the ETFE-PEMs with an IEC of $2.9 \mathrm{mmol} \mathrm{g}^{-1}$ showed a TS of 32 and 8.0 MPa under dry and fully humid conditions ( 0 and $100 \% \mathrm{RH}$ ) at $80{ }^{\circ} \mathrm{C}$, respectively. In particular, PEEK-PEMs with various IECs have higher TS compared with Nafion 212, graft-type ETFE-PEMs, and other aromatic hydrocarbon-type PEMs under severe conditions $\left(80^{\circ} \mathrm{C}, 100 \% \mathrm{RH}\right)$. This is because the hydrophobic PEEK matrix, which prevents severe swelling, possesses high TS (65 MPa for pristine PEEK films) and maintains high TS because of less damage to PEEK substrates during the preparation procedures, thus resulting in better mechanical properties of even PEEK-PEMs with high IECs and containing large volumes of poly(styrene sulfonic acid) grafts.

\section{Morphological changes of PEEK substrates by preparation procedures}

We measured the XRD of the original PEEK, PEEK-DVB, graftedPEEK with a GD of 70\%, and a PEEK-PEM with an IEC of 1.73 $\mathrm{mmol} \mathrm{g}^{-1}$ (sulfonic acid form of the grafted-PEEK). As shown in Fig. 4(a), the original PEEK with a crystallinity of $11 \%$ showed a broad peak centered at $1.3 \AA^{-1}$, originating from an amorphous halo. New peaks at $1.45 \AA^{-1}$ with two recognizable shoulder-like peaks at $1.48 \AA^{-1}$ and $1.62 \AA^{-1}$, assigned to the (110), (111), and (200) planes, appeared upon thermal polymerization of DVB, as shown in Fig. 4(b). In the grafted-PEEK with a GD of $70 \%$ and the corresponding PEEK-PEM with an IEC of $1.73 \mathrm{mmol} \mathrm{g}^{-1}$, new amorphous halos were observed with a peak-center at 1.15 $\AA^{-1}$, attributed to amorphous poly(ETSS) and PSSA graft chains, respectively (Fig. 4(c) and (d)).

The XRD spectrum of the PEEK-DVB, grafted-PEEK with a GD of $70 \%$, and the corresponding PEEK-PEM with an IEC of 1.73 mmol $\mathrm{g}^{-1}$ were well peak-separated into four peaks attributed to the amorphous halo and the (110), (111), and (200) planes by a curve-fitting method, as shown in Fig. 4. The morphological changes induced by PEM preparation procedures (thermal polymerization of DVB, radiation-induced graft-polymerization of ETSS, and hydrolysis of ethyl ester) were evaluated in terms of the degree of crystallinity (DOC), which was calculated using the separated peaks and eqn (7). As can be seen by comparing Fig. 4(a) and (b), thermal treatment for the polymerization of DVB into original PEEK films increased the DOC from 11 to $28 \%$. The DOC of $28 \%$ is in good agreement with that obtained from the melting enthalpy of PEEK crystals in the DSC profile of PEEK-DVB. Because it has been reported that solvent-induced recrystallization of the amorphous PEEK solid proceeded at approximately $50{ }^{\circ} \mathrm{C}$ because of the lowering of the glass transition temperature $\left(T_{\mathrm{g}}\right)$, the amorphous phase in the PEEK substrate recrystallized during thermal graft polymerization of DVB. ${ }^{54-56}$ The DOCs of the grafted-PEEK and PEEK-PEM $(22 \%$ and $18 \%$ ) were lower than that of PEEK-DVB because of the introduction of amorphous poly(ETSS) and PSSA grafts. 


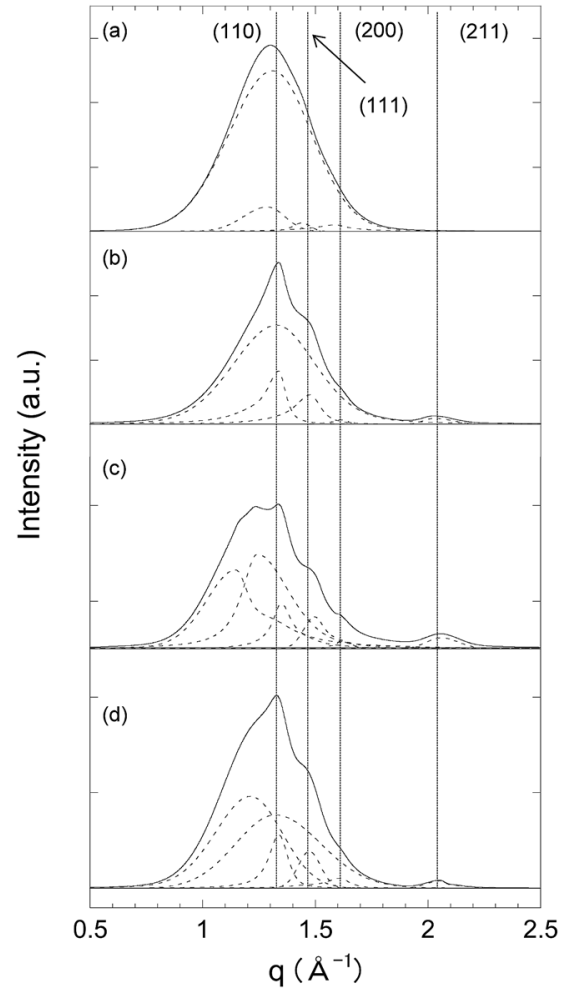

Fig. 4 XRD spectra of (a) PEEK, (b) PEEK-DVB, (c) grafted-PEEK (GD = $70 \%$ ), and (d) PEEK-PEM with an IEC of $1.73 \mathrm{mmol} \mathrm{g}^{-1}$ (sulfonic acid form of the grafted-PEEK). The separated peaks attributed to the amorphous halo and (110), (111), and (200) planes of PEEK ( $a$ and b) with amorphous poly(ETSS) and PSSA graft peaks (c and d) are shown as dotted lines.

However, considering only a PEEK substrate area (in particular, subtracting the graft-polymer phases from the PEMs), the DOC's of these films (namely, subtracting the graft-polymer phases from the PEMs) were $36 \%$ and $31 \%$. Accordingly, the crystallinities of the PEEK substrates increased to some extent during radiation-induced grafting in ETSS/dioxane solution at $80{ }^{\circ} \mathrm{C}$ and hydrolysis in water at $95{ }^{\circ} \mathrm{C}$.

The DOC and DOC' ${ }^{\prime}$ of PEEK-PEMs were plotted as a function of the DOG in Fig. 5. The DOC based on whole membranes in PEEK-PEMs decreased linearly from $18 \%$ to $11 \%$ when the IECs increased from 1.73 to $3.08 \mathrm{mmol} \mathrm{g}^{-1}$, which correspond to GDs of $70 \%$ and $207 \%$, because of the increase in the amounts of incorporated amorphous graft-polymers. However, the DOC' determined on the basis of the PEEK substrate area in PEEKPEMs increased slightly to approximately $31 \%$. We reported that the crystallinity of ETFE-PEMs decreased during severe sulfonation in the dichloroethene solution of chlorosulfonic acid (strong acid) at $60{ }^{\circ} \mathrm{C}$, and damage was induced in the lamellar crystals. ${ }^{45}$ However, the PEEK-PEM preparation process does not involve sulfonation, but only mild hydrolysis in water for preparing PEEK-PEMs. It should be noted that the amorphous phase in PEEK substrates was recrystallized during graft polymerization; thus, the crystallinity of the PEEK substrate in PEEK-PEMs was maintained because of the mild hydrolysis conditions compared with the severe sulfonation conditions that ETFE-PEMs were subjected to, resulting in the enhancement of tensile strength.

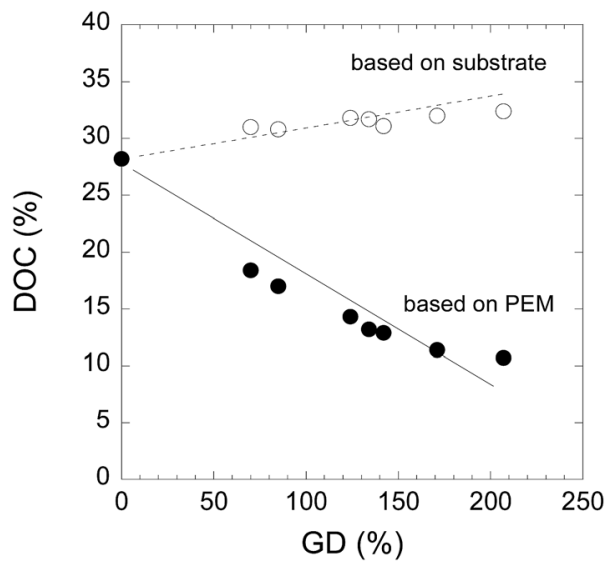

Fig. 5 DOC $(O)$ and $\operatorname{DOC}^{\prime}(0)$ of PEEK-DVB and PEEK-PEMs with IECs of $1.73-3.08 \mathrm{mmol} \mathrm{g}^{-1}$, which are estimated on the basis of PEEKsubstrates and PEMs.

We have reported the $\mathrm{RH}$ dependence of the electrochemical and mechanical properties of ETFE-PEMs. ${ }^{46}$ In the report, SAXS experiments revealed that hydrophilic grafted polymers provide clearer phase separation from the hydrophobic ETFE substrate, thereby maintaining conducting channels even under lower $\mathrm{RH}$ conditions. Therefore, tentatively, we consider that the PEEKPEMs with higher IECs should have similar ion-channels even at lower RH. Unfortunately, compared with the ETFE-PEMs, the aromatic hydrocarbon-based PEEK-PEMs have less information in the SAXS profiles. Thus, we are planning to investigate the morphology of PEEK-PEMs by the combination of SAXS and SANS with a contrast variation method under dry and wet conditions.

\section{Oxidative stability of PEEK-PEMs}

The oxidative stability of PEEK-PEMs with IECs $=1.73,2.36$, and $3.08 \mathrm{mmol} \mathrm{g}^{-1}$ was evaluated as the change in the weight of the membranes in Fenton's reagent $\left(3 \% \mathrm{H}_{2} \mathrm{O}_{2}\right.$ aq., 2 ppm $\left.\mathrm{FeSO}_{4}\right)$ at $80{ }^{\circ} \mathrm{C}$ (Fig. S2 $\dagger$ ). The PEEK-PEMs with high IECs showed low oxidative stability against Fenton's reagent. For example, the oxidative stabilities of poly(phenylene ether)s with sulfonic acid having alkyl side chains in Fenton's reagent $\left(3 \% \mathrm{H}_{2} \mathrm{O}_{2}\right.$ aq., 2 ppm $\mathrm{FeSO}_{4}$ ) at $80{ }^{\circ} \mathrm{C}$ for $1 \mathrm{~h}$ were $81-94 \% .{ }^{17}$ The PEEK-PEMs with higher IEC levels retained their weight in Fenton's reagent after $1 \mathrm{~h}$, and their weights gradually decreased with increasing immersion time. Accordingly, the PEEK-PEMs showed superior oxidative stability than the conventional sulfonated aromatic hydrocarbon-type PEMs because the grafted poly(styrene sulfonic acid)s are well surrounded by PEEK chains, which suppress hydroxyl radical attacks.

\section{Fuel cell performance}

Membrane-electrode assemblies (MEAs) were fabricated using the PEEK-PEM with an IEC of $2.45 \mathrm{mmol} \mathrm{g}^{-1}$ (film thickness of $26 \mu \mathrm{m})$ and Pt ( $\left.0.4 \mathrm{mg} \mathrm{cm}^{-2}\right)$-loaded gas diffusion layers as the anode and cathode catalyst layers, respectively. The fuel cell test of the MEAs was performed at $80{ }^{\circ} \mathrm{C}$ under dry and humid conditions $(30 \%$ and $100 \% \mathrm{RH})$; the current-voltage $(I-V)$ 
polarization curves of the fuel cells are plotted in Fig. 6. Under the completely humidified condition, the PEEK-PEM-based MEA showed a maximum power density $\left(E_{\max }\right)$ of $860 \mathrm{~mW} \mathrm{~cm} \mathrm{~m}^{-2}$ at $2240 \mathrm{~mA} \mathrm{~cm}^{-2}$. The $E_{\max }$ value is somewhat higher than that of other aromatic hydrocarbon-type PEMs and is comparable with that of Nafion $212\left(932 \mathrm{~mW} \mathrm{~cm}^{-2}\right)$, prepared by the same method, under the same operating conditions. This can be explained by the similar conductivity levels of the PEEK-PEM with an IEC of $2.45 \mathrm{mmol} \mathrm{g}^{-1}$ and Nafion 212 at $80{ }^{\circ} \mathrm{C}$ under 95\% RH (0.223-0.261 and $0.155 \mathrm{~S} \mathrm{~cm}^{-2}$ in Fig. 6(a)).

At $30 \% \mathrm{RH}$, the $E_{\max }$ of the PEEK-PEM-based MEA was 826 $\mathrm{mW} \mathrm{cm} \mathrm{cm}^{-2}$ at $2180 \mathrm{~mA} \mathrm{~cm}^{-2}$, which is the $96 \%$ level compared with $100 \% \mathrm{RH}$, whereas that of the Nafion 212-based MEA markedly decreased to the $36 \%$ level $\left(333 \mathrm{~mW} \mathrm{~cm}^{-2}\right.$ at $771 \mathrm{~mA}$ $\mathrm{cm}^{-2}$ ), as generally seen in other aromatic hydrocarbon-type PEM-based MEAs. Apparently, the $E_{\max }$ of the PEEK-PEM-based MEA was 2.5 times higher than that of the Nafion 212-based MEA under $30 \% \mathrm{RH}$ and $80{ }^{\circ} \mathrm{C}$. As mentioned before, the conductivity of PEEK-PEMs exhibited less RH dependence; thus, at 30\% RH, the PEEK-PEM-based MEA with an IEC of 2.45 mmol $\mathrm{g}^{-1}$ showed less RH dependence, thus affording higher maximum power densities compared with aromatic hydrocarbon-type PEMs. Contrary to the comparison with other aromatic hydrocarbon-type PEMs, it is difficult to explain the different power densities of PEEK-PEM- and Nafion 212-based MEAs because of their similar conductivities under $30 \% \mathrm{RH}$. One possible reason for the above difference should be the
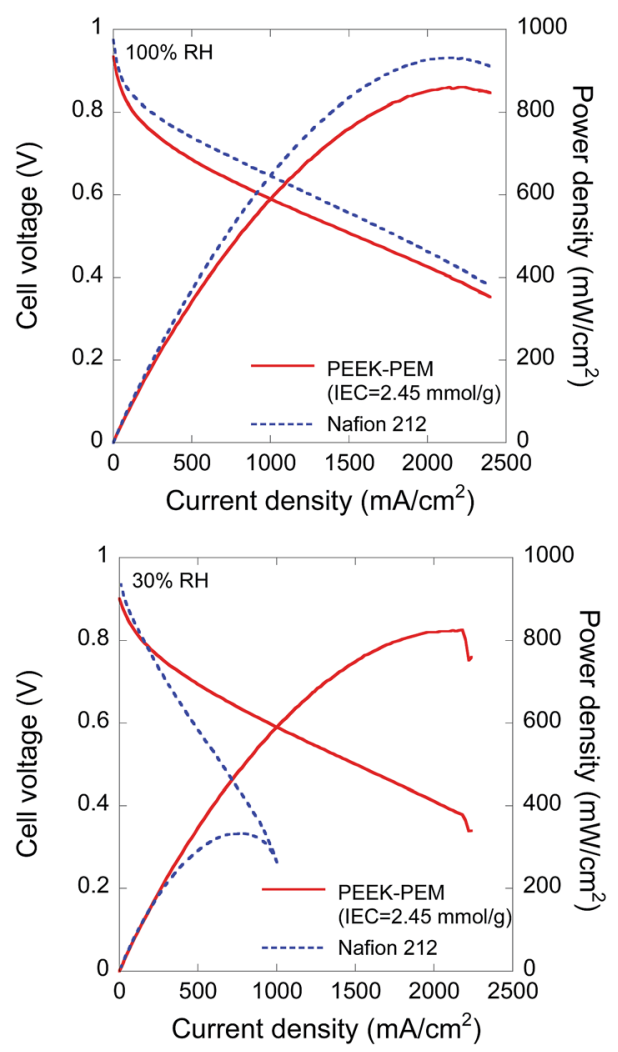

Fig. 6 Fuel cell performance of MEAs fabricated with a PEEK-PEM with an IEC of $2.45 \mathrm{mmol} \mathrm{g}^{-1}$ and Nafion 212: (a) $100 \% \mathrm{RH}$ at $80^{\circ} \mathrm{C}$ and (b) $30 \% \mathrm{RH}$ at $80^{\circ} \mathrm{C}$. different diffusion rates of the water molecules being produced at the cathode, that is, Nafion 212 is well known as a membrane with a remarkably high diffusion coefficient of water, whereas in general, the coefficient is considerably lower in the case of hydrocarbon-type PEMs. Furthermore, as shown in Fig. 2(a), the water uptake of PEEK-PEMs having IECs of around $2.45 \mathrm{mmol} \mathrm{g}^{-1}$ was over $10 \%$ at low $\mathrm{RH}\left(30 \%\right.$ and $\left.80{ }^{\circ} \mathrm{C}\right)$, whereas the water uptake of Nafion 212 under $30 \% \mathrm{RH}$ and $80{ }^{\circ} \mathrm{C}$ was approximately $4 \%$. In other words, the PEEK-PEM-based MEAs contain larger amounts of water molecules because of higher water uptake and poorer diffusion properties than the Nafion 212-based MEAs.

\section{Conclusions}

PEEK-PEMs with IECs in the range of 1.73-3.08 $\mathrm{mmol} \mathrm{g}^{-1}$ showed higher conductivities of $0.001-0.009 \mathrm{~S} \mathrm{~cm}^{-1}$ even under low $\mathrm{RH}$ conditions $(30 \% \mathrm{RH})$. This is because the proton conductivities of PEEK-PEMs are less dependent on $\mathrm{RH}$ compared with other aromatic hydrocarbon-type PEMs. Therefore, the PEEK-PEMs with an IEC of $3.08 \mathrm{mmol} \mathrm{g}^{-1}$ exhibited a similar conductivity to that of Nafion $212\left(0.009 \mathrm{~S} \mathrm{~cm}^{-1}\right)$ even at $30 \% \mathrm{RH}$ probably because of its $17 \%$ water uptake, which is higher than that of Nafion 212 (WU 4.3\%).

Under humid conditions, which test flooding in fuel cells, the PEEK-PEM has 1.4 times higher tensile strength (14 MPa) than Nafion 212. This is because the hydrophobic PEEK matrix prevents severe swelling, which originates from the high tensile strength of pristine PEEK films, thus helping maintain high TS because of less damage to the PEEK substrates.

The MEA fabricated using the PEEK-PEM with an IEC of 2.45 mmol g ${ }^{-1}$ showed $E_{\text {max }}$ values of 860 and $826 \mathrm{~mW} \mathrm{~cm}^{-2}$ under $100 \%$ and $30 \% \mathrm{RH}$, respectively. This implies that the $E_{\max }$ of the PEEK-PEM showed low RH dependence, resulting in 2.5 times higher $E_{\max }$ than that of Nafion 212 at $30 \% \mathrm{RH}$.

$\mathrm{X}$-ray scattering analyses revealed that the crystallinity of approximately $28-32 \%$ was maintained and propagated during graft polymerization of the graft-type PEEK-PEMs. The abovementioned unique structures were the origins of higher conductivity and tensile strengths, respectively, compared with conventional PEMs. Accordingly, PEEK-based graft-type PEMs should have great potential as alternative PEMs for Nafion.

\section{Acknowledgements}

The authors would like to thank Enago for the English language review.

\section{References}

1 B. C. H. Steele and A. Heinzel, Nature, 2001, 414(15), 345352.

2 M. S. Whittingham, R. F. Savinell and T. Zawodzinski, Chem. Rev., 2004, 104, 4243-4244.

3 M. Winter and R. J. Brodd, Chem. Rev., 2004, 4245-4269.

4 R. Borup, J. Meyers, B. Pivovar, Y. S. Kim, R. Mukundan, N. Garland, D. Myers, M. Wilson, F. Garzon, D. Wood, P. Zelenay, K. More, K. Stroh, T. Zawodzinski, J. Boncella, 
J. E. McGrath, M. Inaba, K. Miyatake, M. Hori, K. Ota, Z. Ogumi, S. Miyata, A. Nishikata, Z. Siroma, Y. Uchimoto, K. Yasuda, K. Kimijima and N. Iwashita, Chem. Rev., 2007, 107, 3904-3951.

5 Q. Li, R. He, J. O. Jensen and N. J. Bjerrum, Chem. Mater., 2003, 15, 4896-4915.

6 B. Smitha, S. Sridhar and A. A. Khan, J. Membr. Sci., 2005, 259, 10-26.

7 S. Zhong, C. Liu and H. Na, J. Membr. Sci., 2009, 326, 400-407. 8 X. Wu, G. He, X. Li, F. Nie, X. Yan and L. Yu, J. Power Sources, 2014, 246, 482-490.

9 E. A. Weiber, S. Takamuku and P. Jannasch, Macromolecules, 2013, 46, 3476-3485.

10 M. Schuster, C. C. de Araujo, V. Atanasov, H. T. Andersen, K.-D. Kreuer and J. Maier, Macromolecules, 2009, 42, 3129-3137. 11 C. Wang and S. J. Paddison, Soft Matter, 2014, 10, 819-830.

12 S. Takamuku, A. Wohlfarth, A. Manhart, P. Räder and P. Jannasch, Polym. Chem., 2015, 6, 1267-1274.

13 J. Pang, S. Feng, Y. Yu, H. Zhang and Z. Jiang, Polym. Chem., 2014, 5, 1477-1486.

14 Y. Yin, Q. Du, Y. Qin, Y. Zhou and K. Okamoto, J. Membr. Sci., 2011, 367, 211-219.

15 K. Miyatake, H. Furuya, M. Tanaka and M. Watanabe, J. Power Sources, 2012, 204, 74-78.

16 K. H. Lee, S. Y. Lee, D. W. Shin, C. Wang, S.-H. Ahn, K.-J. Lee, M. D. Guiver and Y. M. Lee, Polymer, 2014, 55, 1317-1326.

$17 \mathrm{X}$. Zhang, L. Sheng, T. Hayakawa, M. Ueda and T. Higashihara, J. Mater. Chem. A., 2013, 1, 11389-11396.

18 X. Zhang, L. Sheng, T. Higashihara and M. Ueda, Polym. Chem., 2013, 4, 1235-1242.

19 F. Ng, D. J. Jones, J. Rozière, B. Bauer, M. Schuster and M. Jeske, J. Membr. Sci., 2010, 362, 184-191.

20 S. Angioni, D. C. Villa, S. D. Barco, E. Quartarone, P. P. Righetti, C. Tomasi and P. Mustarelli, J. Mater. Chem. A., 2014, 2, 663-671.

21 L. Sheng, T. Higashihara, M. Ueda and T. Hayakawa, J. Polym. Sci., Part A: Polym. Chem., 2014, 52, 21-29.

22 K. H. Lee, S. Y. Lee, D. W. Shin, C. Wang, S.-H. Ahn, K.-J. Lee, M. D. Guiver and Y. M. Lee, Polymer, 2014, 55, 1317-1326.

23 S. Chen, R. Hara, K. Chen, X. Zhang, N. Endo, M. Higa, K. Okamoto and L. Wang, J. Mater. Chem. A, 2013, 1, 8178-8189.

24 J. R. Rowlett, Y. Chen, A. T. Shaver, O. Lane, C. Mittelsteadt, H. Xu, M. Zhang, R. B. Moore, S. Mecham and J. E. McGrath, Polymer, 2013, 54, 6305-6313.

25 T. Hoshi, B. Bae, M. Watanabe and K. Miyatake, Bull. Chem. Soc. Jpn., 2012, 85, 389-396.

26 K. Miyatake, D. Hirayama, B. Bae and M. Watanabe, Polym. Chem., 2012, 3, 2517-2522.

27 N. Li, S. Y. Lee, Y.-L. Liu, Y. M. Lee and M. D. Guiver, Energy Environ. Sci., 2012, 5, 5346-5355.

28 Y. Chang, G. F. Brunello, J. Fuller, M. L. Disabb-Miller, M. E. Hawley, Y. S. Kim, M. A. Hickner, S. S. Jang and C. Bae, Polym. Chem., 2013, 4, 272-281.

29 T. Shimura, M. Watanabe and K. Miyatake, RSC Adv., 2012, 2, 5199-5204.

30 K. Nakabayashi, T. Higashihara and M. Ueda, Macromolecules, 2011, 44, 1603-1609.
31 J. Park, K. Enomoto, T. Yamashita, Y. Takagi, K. Todaka and Y. Maekawa, J. Membr. Sci., 2013, 438, 1-7.

32 K. Enomoto, S. Takahashi, R. Rohani and Y. Maekawa, J. Membr. Sci., 2012, 415-416, 36-41.

33 K. Enomoto, S. Takahashi, T. Iwase, T. Yamashiata and Y. Maekawa, J. Mater. Chem., 2011, 21, 9343-9349.

34 J. Chen, D. Li, H. Koshikawa, M. Zhai, M. Asano, H. Oku and Y. Maekawa, J. Membr. Sci., 2009, 344, 266-274.

35 J. Chen, M. Zhai, M. Asano, L. Huang and Y. Maekawa, J. Mater. Sci., 2009, 44, 3674-3681.

36 S. Hasegawa, K. Sato, T. Narita, Y. Suzuki, S. Takahashi, N. Morishita and Y. Maekawa, J. Membr. Sci., 2009, 345, 74-80.

37 S. Hasegawa, Y. Suzuki and Y. Maekawa, Radiat. Phys. Chem., 2008, 77, 617-621.

38 J. Chen, M. Asano, Y. Maekawa and M. Yoshida, J. Membr. Sci., 2006, 277, 249-257.

39 J. Chen, M. Asano, T. Yamaki and M. Yoshida, J. PowerSources, 2006, 158, 69-77.

40 K. Sato, S. Ikeda, M. Iida, A. Oshima, Y. Tabata and M. Washio, Nucl. Instrum. Methods Phys. Res., Sect. B, 2003, 208, 424-428.

41 T. Yamaki, M. Asano, Y. Maekawa, Y. Morita, T. Suwa, J. Chen, N. Tsubokawa, K. Kobayashi, H. Kubota and M. Yoshida, Radiat. Phys. Chem., 2003, 67, 403-407.

42 L. Gubler, Adv. Energy Mater., 2014, 4, 1300827.

43 K. Jetsrisuparb, S. Balog, C. Bas, L. Perrin, A. Wokaun and L. Gubler, Eur. Polym. J., 2014, 53, 75-89.

44 S. A. Gürsel, L. Gubler, B. Gupta and G. G. Scherer, Adv. Polym. Sci., 2008, 215, 157-217.

45 T. T. Duy, S. Sawada, S. Hasegawa, Y. Katsumura and Y. Maekawa, J. Membr. Sci., 2013, 447, 19-25.

46 T. D. Tap, S. Sawada, S. Hasegawa, K. Yoshimura, Y. Oba, M. Ohnuma, Y. Katsumura and Y. Maekawa, Macromolecules, 2014, 47(7), 2373-2383.

47 S. Hasegawa, S. Takahashi, H. Iwase, S. Koizumi, N. Morishita, K. Sato, T. Narita, M. Ohnuma and Y. Maekawa, Polymer, 2011, 52, 98-106.

48 S. Hasegawa, S. Takahashi, H. Iwase, S. Koizumi, M. Ohnuma and Y. Maekawa, Polymer, 2013, 54, 2895-2900. 49 Z. Pu, L. Chen, Y. Long, L. Tong, X. Huang and X. Liu, J. Polym. Res., 2013, 20, 281.

50 J. Pang, S. Feng, Y. Yu, H. Zhang and Z. Jiang, Polym. Chem., 2014, 5, 1477-1486.

51 K. H. Lee, S. Y. Lee, D. W. Shin, C. Wang, S.-H. Ahn, K.-J. Lee, M. D. Guiver and Y. M. Lee, Polymer, 2014, 55, 1317-1326.

52 L. Sheng, T. Higashihara, M. Ueda and T. Hayakawa, J. Polym. Sci., Part A: Polym. Chem., 2014, 52, 21-29.

53 X. Zhang, L. Sheng, T. Hayakawa, M. Ueda and T. Higashihara, J. Mater. Chem. A, 2013, 1, 11389-11396.

54 E. J. Stober, J. C. Seferis and J. D. Keenan, Polymer, 1984, 25, 1845-1852.

55 M. A. Grayson and C. J. Wolf, J. Polym. Sci., Part B: Polym. Phys., 1988, 26, 2145-2167.

56 C. J. Wolf, J. A. Bornmann, M. A. Grayson and D. P. Anderson, J. Polym. Sci., Part B: Polym. Phys., 1992, 30, 251-257. 